\title{
Trajectories of Poverty and Economic Hardship among American Families Supporting a Child with a Neurodisability
}

\author{
David W. Rothwell, Ph.D. ${ }^{a}$ \\ david.rothwell@oregonstate.edu; Waldo Hall 460, College of Public Health and Human \\ Sciences, Oregon State University, Oregon, USA 97331 \\ Geneviève Gariépy, Ph.D. \\ genevieve.gariepy@mail.mcgill.ca; Institute for Health and Social Policy, McGill University, \\ Montreal, Quebec, Canada \\ Frank J. Elgar, Ph.D. \\ frank.elgar@mcgill.ca; Institute for Health and Social Policy, McGill University, Montreal, \\ Quebec, Canada \\ Lucyna M. Lach, Ph.D. \\ lucy.lach@mcgill.ca; 3506 University Street, School of Social Work, McGill University, \\ Montreal, Quebec, Canada
}

${ }^{\text {a }}$ Corresponding author. 


\section{Acknowledgements}

The collection of PSID data used in this study was partly supported by the National Institutes of Health under grant number R01 HD069609 and the National Science Foundation under award number 1157698 . The second author was supported by postdoctoral funding from the Canadian Institutes of Health Research. This research was supported by a grant from the Kids Brain Health Network of Canada. 
Trajectories of Poverty and Economic Hardship among American Families Supporting a Child with a Neurodisability 


\begin{abstract}
Caring for a child with a neurodisability (ND) impacts the financial decisions, relationships, and well-being of family members. Using the Panel Study of Income Dynamics (PSID), we tracked families from 5 years before child with ND birth until the child reached 20 years of age and used latent growth curve modeling to estimate different trajectories for risk of two indicators: poverty and economic hardship. In bivariate terms, families raising a child with ND had higher risks of poverty and economic hardship across time. Five latent growth trajectories were identified for each indicator. After controlling for family and caregiver characteristics that preceded the birth of the child with an ND, families raising a child with a ND were more likely to experience persistent economic hardship. However, raising a child with a ND was not associated with a unique poverty risk, suggesting that families already in poverty are more likely to remain poor if they have a child with a ND. The study establishes descriptive evidence for how having a child with a ND relates to changes in family economic conditions. The importance of social and economic conditions that precede the child's birth lend support for a social causation framework of health inequalities.
\end{abstract}

Keywords: poverty; economic hardship; neurodisability; longitudinal; PSID; families 
The past fifty years have witnessed a major increase in childhood disabilities. The overall prevalence of children with activity limitations has increased fourfold; among those with activity limitations, disorders that are developmental, emotional and behavioural in nature have increased, while the proportion associated with physical health conditions (e.g., cerebral palsy) has declined (Halfon, Houtrow, Larson, \& Newacheck, 2012). Children with neurodisabilities (ND) can be located in both of these groups as they have "congenital or acquired long-term conditions that are attributed to impairment of the brain and/or neuromuscular system” (Morris, Janssens, Tomlinson, Williams, \& Logan, 2013, p. 1103). Associated with the ND are difficulties with movement, cognition, hearing and vision, communication, emotion, and behavior. Presently, one in ten families in North America care for a child with a diagnosis that is consistent with the definition of a neurodisability (Arim et al., 2012; Lach et al., 2009; Zablotsky, Black, Maenner, Schieve, \& Blumberg, 2015). Recent estimates from the National Health Interview Survey reveal that families caring for a child with ND are more likely to be living in poverty than those whose children do not have a ND. And, there is a strong socioeconomic gradient, with the prevalence of an observed limitation in a child's usual activities being 1.9 times greater for families below the poverty threshold than in families $400 \%$ or more above the poverty threshold (Halfon et al., 2012). Yet, relatively few studies have examined how the economic circumstances of families with a ND child change throughout the family life course. And, to our knowledge, no studies have examined socioeconomic conditions of families prior to the birth of the ND child. This longitudinal study adds to the literature by examining the poverty and economic hardship of families before and after the birth of the child with ND. The purpose is to improve understanding of the diverse economic trajectories and challenges faced by families supporting children with ND. 


\section{Background}

Poverty—having insufficient resources to meet a minimum standard set of needs (Smeeding, 2016) — is typically measured at the household level because members of households share economic resources such as income and social assistance benefits. An estimated $14.8 \%$ of the US population and $21.1 \%$ of all children live below the poverty threshold set by the US Census Bureau (DeNavas-Walt \& Proctor, 2015). The addition of a child to a household increases the risk of poverty because children increase the resource needs without adding resources. While many nation states use child benefits and tax credits to offset this poverty risk, income transfers in the US to families with children are relatively meager (Rainwater \& Smeeding, 2005). In the context of a weak social safety net, certain risk factors such as having a child with ND may pose relatively high poverty risk for American families.

Growing up poor has lifelong consequences for children’s health and development. Children in poverty face more academic and social challenges and have worse long-term health and economic outcomes (American Academy of Pediatrics, 2016; Duncan \& BrooksGunn, 1999; Duncan, Ziol-Guest, \& Kalil, 2010; Hertzman, 1999; Pascoe et al., 2016). These outcomes relate not only to poverty severity but also to its cumulative effects over time. Seminal work on poverty dynamics found that many families have short spells of poverty and a much smaller proportion experience long duration of poverty (e.g., Bane \& Ellwood, 1986). However, persons with a disability are more likely than those without a disability to experience a poverty spell of 12 months or longer (Brault, 2010). Much less is known about the poverty dynamics of families raising children with a neurodisability.

For several reasons, the economic, social, and health burdens of NDs deepen and compound the impact of poverty. First, caring for a child with ND is expensive in terms of direct out-of-pocket expenses of managing the condition and indirect costs in terms of the 
time needed to care for the child (Anderson, Dumont, Jacobs, \& Azzaria, 2007; Genereaux, van Karnebeek, \& Birch, 2015; Lavelle et al., 2014; Saunders et al., 2015; Stabile \& Allin, 2012). Saunders et al. (2015) found that about two-thirds of mothers of children with autism spectrum disorder or intellectual disability reduced their work hours or stopped working altogether to care for their child. A study by Cidav et al. (2012) found that mothers of children with autism spectrum disorder were 6\% less likely to be employed, worked 7 hours less per week, and earned 56\% less on average than mothers of children with no limitation. Other evidence from the disability literature indicates that maternal labor activity is reduced when a child has a disability, particularly during the early childhood years (Burton \& Phipps, 2009; Lu \& Zuo, 2010; Porterfield, 2002; Stabile \& Allin, 2012; Wehby \& Ohsfeldt, 2007). ${ }^{1}$ This suggests that the birth of a child with a ND may increase a family's economic hardship as well as their likelihood of poverty via reduced labor market activity.

Second, while families with a child with a ND are distributed throughout the social hierarchy, such families are more likely to be located in lower socioeconomic positions. This pattern of unequal distribution holds across a diverse range of countries using different strategies of identification (Emerson \& Hatton, 2009). Gender and family structure illustrate this phenomenon. Children with disabilities are more likely than other children to be cared for by females (Cohen \& Petrescu-Prahova, 2006; Lewis, Kagan, \& Heaton, 2000). Since the caregiver burden falls disproportionately along gender lines, women with children with ND must manage the tension between fulfilling the demands of caregiving and pursuing labor market opportunities. Often the former takes priority, which results in an increased risk of poverty. This pattern can be exacerbated in social welfare systems that maintain weak safety nets. Family structure is another pathway through which disability is socially stratified. Mothers of children with ND are less likely to marry and those who do are more likely to

\footnotetext{
${ }^{1}$ Stabile and Allin (2012) provide a thorough review of studies examining the impact on employment.
} 
divorce than mothers of children without a ND (Joesch \& Smith, 1997; Kvist, Nielsen, \& Simonsen, 2013; Mauldon, 1992). Single parent families are at greater risk for poverty by way of having one less income earner and less help with household and child-rearing tasks. Third, other characteristics differentiate families raising a child with a ND. Social epidemiologists point to the cascade of social and economic consequences associated with managing the disability (health selection path) and, conversely, the family socioeconomic circumstances associated with those who do and do not have a child with a ND (social causation path). Through health selection, differences in health status directly affect socioeconomic position (Kröger, Pakpahan, \& Hoffmann, 2015). The idea is that, via selection, healthy young people are better able to achieve greater social and economic status later in life, while the opposite trajectory holds for those with health concerns. Therefore, the presence of child with a ND is likely to lead to less favorable social and economic outcomes for the family due to its impact on the earning capabilities of parents and caregivers. The social causation theory suggests that those living in lower socioeconomic (SES) conditions will have worse health later in life. Limited access to resources, social supports, and knowledge stratifies population health early in life (Palloni, Milesi, White, \& Turner, 2009; Power, Stansfeld, Matthews, Manor, \& Hope, 2002). When applied to families who have a child with a ND, social causation would predict that families who were better off before their child was born would fare better than those who are living in more compromised SES conditions. In other words, the economic consequences typically associated with the ND would not be explained by the child's health status, per se, but by the pre-existing SES position.

Although the evidence of association between childhood disability and poverty is irrefutable (Blackburn, Spencer, \& Read, 2013; Fujiura \& Yamaki, 2000; Lustig \& Strauser, 2007; Stabile \& Allin, 2012), the direction of influence remains unclear due to common 
social and economic factors that contribute to-and result from—child NDs. Few datasets allow researchers to estimate the lifetime patterns of experiencing poverty risk. One study suggests that by late middle adulthood (age 60), 23\% of Americans will experience 1 or more years of poverty and the total years for those who experienced more than 1 year of poverty was 13 (Rank \& Hirschl, 2001). While previous research has examined poverty trajectories and health across the life course (McDonough, Sacker, \& Wiggins, 2005), few have examined the poverty risk for families raising children with a ND across the life course. The few longitudinal studies point to mixed results. For example, in a study over four years (2001-2005), Shahtahmasebi et al (2011) found a positive bivariate association between families supporting a disabled child and poverty duration, yet this disappeared when contemporaneous family characteristics such as family structure, age, and health status of caregiver were controlled. Yet, in another study over a shorter one-year period, families supporting a child with a disability were significantly more likely to experience poverty and hardship (Emerson, Shahtahmasebi, Lancaster, \& Berridge, 2010). The extent to which caring for a child with a ND places families at greater economic hardship and risk of poverty over a longer run of the life course remains unclear.

Estimating how raising a child with a ND affects family economic outcomes presented several challenges. We guarded against selection bias by analyzing data from a long-run intergenerational panel study that enabled us to look back at the socioeconomic conditions of families before having a child with a ND. The longitudinal design also allowed us to consider how life course and ND status interact to affect poverty risk by modeling latent trajectories across the family life course and then estimating how having a child with an NDD relates to these trajectories.

The study was guided by the following questions: (i) how does the risk of poverty for families raising a child with a ND vary over time? (ii) what are the poverty risk trajectories 
that families experience over time? And, (iii) is having a child with a ND associated with trajectories that experience more poverty risk? In addition to poverty, we also measured a less conservative indicator of economic hardship. We hypothesized that families of children with a ND would follow less favorable poverty and hardship trajectories. Further, guided by the social causation hypothesis, we expected that pre-birth socioeconomic conditions of families influence later poverty risk. The birth of the child with a ND, having greater importance than pre-existing social conditions in shaping later economic circumstances, would indicate more support for social causation.

\section{Methods}

\section{Study population}

The Panel Study Of Income Dynamics (PSID) is a nationally representative longitudinal household survey of over 9,000 American families followed annually from 1968-1997 and biennially from 1997 to the present (Institute for Social Research, 2015). In 1997, the PSID initiated the Child Development Supplement (CDS) to collect information on children of the cohort. Three waves of CDS data are available. The CDS-I (1997-98) completed interviews with 2,394 families, providing information on 3,563 children aged 0-12 years (88\% response rate). PSID families with children aged 0-12 years were randomly sampled, with up to two children per family. In-person interviews were conducted with the primary caregivers (usually the mother), and assessments were conducted with children. The CDS-II (2002-03) re-interviewed 2901 children (84\% of those eligible) and the CDS-III (2007-2008) re-interviewed 1506 children (90\% of those eligible). We linked data from CDS participants to PSID parental data thus providing information on families from 1968 up to 2013, when CDS participants were between 16-28 years old. We excluded children with missing information on age and year of birth $(n=246)$ for a final sample size of 3,317 
children. Therefore, we use a total of 25 years per household (5 years before the birth to age 20) constituting 3,317 family-years.

\section{Measures}

\section{Neurodisability}

In the CDS data collection, parents were asked about a list of health conditions and if they were diagnosed by a doctor or a health professional. We categorized children as having a ND if any of the following six conditions was reported during any of the CDS surveys: epilepsy, speech impairment, retardation, developmental delay, autism, and learning disability. Similar strategies have been used in studies that focus on family outcomes in the context of child ND (Garner et al., 2013; Lach et al., 2009).

\section{Family poverty and economic hardship}

The PSID collected detailed information on total family income at every survey wave. The PSID defines families as economically independent households whose members share household finances. Members are related by birth/adoption, marriage or cohabitation. Family income is the sum of all taxable income, transfer income and social security income of all family unit members. We analyzed two economic indicators. The first was absolute family poverty using year-specific national poverty threshold (United States Census Bureau, 2015). This Official Poverty Measure (OPM) considers most sources of cash income as resources and uses a family-size adjusted need threshold. Poverty status is a dichotomous value represented as 1 for below the official poverty threshold and 0 if above the threshold. The OPM is limited in two ways. In absolute terms, the underlying basis for the thresholds have not been updated since their inception in the late 1950s, although the thresholds have been indexed for inflation since that time. Furthermore, in relative terms, the OPM was at about $49 \%$ of the median household income at the time of construction whereas recent estimates place the current OPM threshold around 25\% (Blank, 2008). Because the OPM might not 
accurately reflect need in contemporary society, we constructed a second indicator of economic hardship based on the income-to-needs ratio. This ratio was defined as family income relative to the poverty threshold, where 1.0 represents a family income at the poverty line. We set the family economic hardship at $150 \%$ or below the income-to-needs ratio based on previous poverty research (Shaefer, Edin, \& Talbert, 2015). Broader indicators of poverty such as our measure of economic hardship are often used to determine eligibility forms of social assistance.

\section{Covariates}

Several baseline sociodemographic factors could potentially confound the association between having a child with a ND and the trajectories of family income. To account for this, we included the following covariates for the primary caregiver and household measured in the year prior to the birth year of the child: age, race/ethnicity, years of education, marital status (married/living with partner vs not), employment status (currently working vs not), self-rated health (good/very good/excellent vs fair/poor), and number of children. We did not control for the gender of the primary caregiver because a large majority (97.1\%) were women. We also measured child gender and year of birth of the child.

\section{Statistical analysis}

We defined time zero as the birth year of the child in the CDS. In a first step, we conducted pooled logistic regressions to model the probability of family poverty and economic hardship over time (i.e., by the age of the child) by ND status. We included ND status, time (age) and an interaction between time and ND status to allow the association between ND and poverty to vary over time. We then plotted the predicted probabilities of poverty and economic hardship by time and NDD status.

In a second step, following previous work on income dynamics (Wolf, Gennetian, Morris, \& Hill, 2014), we identified distinct poverty and hardship trajectories from latent 
class growth modelling (LCGM) (Andruff, Carraro, Thompson, Gaudreau, \& Louvet, 2009) using the traj command in Stata 14 (Jones, Nagin, \& Roeder, 2001). LCGM is a semiparametric technique used to uncover distinct groups that follow a similar pattern of change over time. LCGM is sometimes referred to as group-based trajectory analysis and is noted for its person-based (as opposed to variable based approach) for the exploration of development outcomes across time (Nagin, 1999). The procedure assumes that missing data on the dependent variable (e.g., poverty) are missing at random and therefore includes subjects with some missing data on the dependent variable in analysis. The LCGM incorporated sampling weights at the household level from the CDS. We selected the number of trajectories based on the Bayesian Information Criterion (BIC), interpretability of the model, and meaningfulness of each class. The shape of the trajectories in the final model was selected based on the significance of the polynomial components of each class. Participants were classified in the trajectory group for which they had the highest probability of belonging. We then examined whether having a child with ND and family sociodemographic factors predicted the type of poverty trajectory that family would likely experience for the next 20 years by running multinomial logistic regression. We repeated the same steps to identify trajectories for economic hardship. Statistical analyses were conducted in Stata (version 14.1, Stata Corp, College Station, TX).

\section{Results}

We identified 656 children with a ND in the sample (weighted prevalence 20.3\%). Table 1 presents socioeconomic characteristics of families with and without a child with a ND at baseline (birth year of child). Primary caregivers of children with a ND had similar sociodemographic profiles to other primary caregivers but were less likely to be married. Caregivers raising a child with an ND were less likely to work compared to those whose children did not have a ND (42\% and 51\%) and were more likely to report fair or poor health 
(11\% vs 6\%). As expected, more families of children with a ND were economically disadvantaged at baseline (i.e., year of childbirth) with lower median household income and a smaller income-to-needs ratio compared to non-ND families. At baseline, ND families had a greater prevalence of poverty at $18.3 \%$ (95\% CI 13.9, 22.6\%) compared to $11.5 \%$ (95\% CI 9.8, 13.2\%) in those without a child with a ND, a difference of $6.7 \%(95 \%$ CI $2.0,11.4)$ which was statistically significant. In terms of economic hardship, we observed larger differences between groups at baseline, with 30.4\% (95\% CI 25.2, 35.6) of ND families below the $150 \%$ threshold compared to $19.7 \%$ (95\% CI 17.6, 21.9) of non-ND families.

[insert Table 1 about here]

Next, we plotted the risk of poverty and economic hardship for ND families and nonND families before childbirth and across the course of the child's development (Figure 1). The long-running PSID longitudinal data structure generates dynamic insights into the economic circumstances of families over their development. At five years before birth, we found very little difference in the poverty risk across groups (difference of 1.6\%, 95\% CI 2.2, 5.3), but leading up to time zero (childbirth) the economic circumstances diverge considerably. When the risk was averaged across the entire five-year period before birth, families who would have a child with a ND experienced on average a 5.4\% (95\% CI 3.5, 7.3) higher probability of poverty. During the 20 years postnatal, families of children with a ND continued to have a $5.1 \%$ (95\% CI 3.9, 6.2) higher average probability of living in poverty year over year (Figure 1a). Consistent with previous research on the risk of poverty across the life cycle (Rank \& Hirschl, 2001), the risk of poverty was higher in the younger child years. The level of difference in poverty risk was mostly constant until dropping for both groups around age 10 .

[insert Figure 1 about here] 
Differences across groups over time were also observed for economic hardship (see Fig 1b). Because the economic hardship indicator used a more relaxed cutoff (150\% of the poverty line) we found that the prevalence of hardship was greater than the prevalence of poverty for all families. During the five years prior to childbirth, ND families had on average an $8.5 \%$ (95\% CI 6.1, 10.9\%) higher probability of experiencing hardship compared to nonND families. Figure 1b shows how the risk of economic hardship fell with the age of the child and the levels of difference (gaps between groups) were mostly constant across time. From birth to age 20 the average predicted probability of economic hardship was $8.2 \%$ (95\% CI 6.8, 9.6) higher for ND families compared to non-ND families. In relation to poverty presented in Figure 1a, larger differences between ND and non-NDD families were observed for economic hardship five years prior to childbirth (difference of 8.5\%, 95\% CI 6.1, 10.9).

Turning to the LCGMs, the best model fit included five distinct trajectories patterns of family poverty for the period ranging from 5 years before to 20 years after childbirth (see Figure 2a). The first and largest trajectory was persistent non-poverty (57.4\% of the sample; average probability of class membership: 0.93, 99\% CI 0.92, 0.93). Membership in this group was characterized by a constantly low likelihood of experiencing poverty. Of the remaining four trajectories, two experienced decreasing probability of poverty after the birth of the child. The second largest group overall was fast exit out of poverty (14.1\% of the sample; average probability of class membership: $0.79,99 \%$ CI $0.76,0.81$ ), which included families with moderate poverty risk in the early years that declined rapidly over time. Next, the smallest group by proportionate size was the slow exit out of poverty group (6.5\%; average probability of class membership: $0.86,99 \%$ CI $0.83,0.89$ ). Families in this category had the highest probability of poverty before the childbirth but this high risk declined steadily. By age 6, this group had moderate risk of poverty. The remaining two groups saw increases in poverty risk over time until about age 10 . The transient poverty $(13.5 \%$; average probability 
of class membership: 0.83 , 99\% CI $0.81,0.85$ ) started the period with very low risk of poverty that increased steadily. Between age 7 and 20 this group had the second highest risk of poverty. Last was the persistent poverty group (8.6\%; average probability of class membership: 0.93, 99\% CI 0.91, 0.95). This group had the highest probability of being poor from the time of childbirth onwards.

Similar latent trajectory patterns were observed for economic hardship (See Fig 2b). As expected, compared to the poverty trajectories there were fewer families in persistent nonhardship (49.0\% of the sample, average probability of class membership: 0.95, 99\% CI 0.94, 0.96). The slow exit out of hardship (10.4\%, average probability of class membership: 0.89 , $99 \%$ CI $0.87,0.91)$ group trajectory was roughly comparable with the same group on poverty, with high initial hardship risk 5 years prior to child birth that declined steadily over time. The remaining three groups saw the risk of hardship increase. The persistent hardship (18.7\%, average probability of class membership: 0.93, 99\% CI 0.92, 0.94) group started with a high probability and continued that until around child age 15 when the likelihood started to decline but was still the highest by child age 20. With the more relaxed threshold cutoff, this group was, as expected, proportionately larger than the persistently poor group in Fig 2a (18.7\% vs. $8.6 \%)$. The long transient hardship (14.3\%, average probability of class membership: $0.86,99 \%$ CI $0.84,0.90)$ matched the shape of trajectory for the transient poverty group with very low initial probability that peaked at about the age of 10 . From age 8 onward, this group experienced the second highest risk of hardship. The largest difference between poverty and hardship was observed for the short transient hardship group (7.5\%, average probability of class membership: $0.81,99 \%$ CI $0.78,0.84)$. Families in this trajectory experienced a spike in hardship risk from age -5 to 4 , and then the risk virtually disappeared by the teenage years.

[insert Figure 2 about here] 
Examination of the compositions of the five groups provided a deeper understanding of these trajectories (Tables 2 and 4). Race/ethnicity of the primary caregiver closely related to poverty risk. For example, approximately $78 \%$ of the persistent poverty group was nonwhite, compared to a roughly $78 \%$ white race/ethnicity composition in the persistent nonpoverty group. As expected, higher educated caregivers had less poverty risk. Family structure played a significant role among the three groups that showed dynamic movement in and out of poverty (trajectories 2, 3, and 4). Trajectory 2 (fast exit out of poverty) had 61\% of members married or partnered at baseline, compared to the $25 \%$ among trajectory 4 (slow exit) group. As well, the slow exit out of poverty group had the highest proportion of children with NDD (33\%).

\section{[insert Table 2 about here]}

Next, we estimated multinomial models to predict trajectories based on baseline covariates. Table 3 shows results for poverty and Table 5 shows results for economic hardship. We proceeded systematically and started with the ND status of the child. Compared to other families without a child diagnosed with a ND and in reference to the non-poverty trajectory, families with a child with a ND had a $118 \%$ greater probability of experiencing a slow exit out of poverty $(95 \%$ CI 33, 293) and a 91\% greater probability (95\% CI 21, 202) of experiencing persistent poverty. Further, families with a child with ND also had elevated risk for experiencing transient poverty and fast exits out of poverty (68\% greater probability (95\% CI 19, 138 and 50\% greater probability (95\% CI 6, 114), respectively) (Table 3). These results suggest, at a bivariate level, that having a child with a ND was associated with greater risk of belonging to the non-poverty group and the greatest single probability was membership into the slow exit out of poverty group. After adjustment for family sociodemographic factors in the year preceding childbirth, the child's ND status was no longer significantly associated with a specific income trajectory pattern (Table 3). For 
example, the probability of experiencing a slow exit out of poverty and persistent poverty reduced by 40 and $44 \%$, respectively.

[insert Table 3 about here]

A mostly similar pattern was observed for economic hardship. The composition of the persistent hardship trajectory revealed strong patterns of disadvantage (see Table 4). This group (Trajectory 5) was younger, more likely to be minority, with low years of education, more children, and worse self-rated health. At baseline, members of this group were much more likely to be unmarried that members of the other trajectories.

[insert Table 4 about here]

Model 1 of the multivariate results (Table 5) shows that the presence of a child with a ND in the family was associated with higher likelihood of all trajectories, ranging from 53\% more likely to be in the short transient group (Trajectory 2) to 85\% more likely of being in the slow exiting out of hardship group (Trajectory 4). After adjustment for child and family factors, families raising a child with a ND were no longer likely to be in Trajectory 2 or Trajectory 3, but were 74\% more likely than non-ND families to be in Trajectory 4 and 119\% more likely to be in Trajectory 5 (persistent hardship). Even after adjustment for primary caregiver characteristics before birth, ND families were still 115\% more likely to belong to Trajectory 5 that experienced persistent hardship prior to and throughout the child's development.

[insert Table 5 about here]

\section{Discussion}

This study used longitudinal data from a large, 25-year panel to investigate economic trajectories in families with and without a child with NDs. The results underscore the challenging economic conditions faced by families raising a child with a ND. First, children who had ND were more likely than children without an ND to be born into poor families. At 
the time of the child's birth, the ND families in the observed cohort had a poverty rate that was 6 percentage points higher than in families who were not raising a child with a ND. The proportion of families experiencing economic hardship was 10 percentage points higher in the ND families. This finding indicates a significant socioeconomic disparity even before the birth of a child who is diagnosed with a ND. Simply put, families that would eventually have a child diagnosed with a NDD were more likely to be poor and in economic hardship, which was consistent with the national statistics from the U.S. Census (Brault, 2010).

Second, whilst the risks of poverty and hardship declined somewhat during the subsequent 20 years, the socioeconomic difference between ND and non-ND families remained largely intact. In other words, in two decades the families of children with a ND were never able to close the economic gap. The peak risk for poverty and hardship appeared to hit families when the child was around 5 years of age, when caregiving responsibilities and expenses were perhaps most demanding. These findings are consistent with the social causation framework as these social conditions at birth explained future economic trajectories better than health selection.

Third, our analysis of trajectories in poverty risk revealed certain characteristics of families in persistent poverty and hardship. Comprising 9 and 19\% of the sample, families in persistent poverty and hardship had relatively younger primary caregivers, lower levels of human capital (levels of education), more single parents (i.e., not married or partnered), and parents that were in poor health. Just 30\% of parents in the persistent hardship group were employed at baseline and more than one in every four of these families had a child with a ND. Moreover, having a child with an ND put families at greater risk of persistent hardship, even after adjusting for other child, family, and caregiver characteristics. Caring for a child with a ND, especially during the first 10 years, may have exerted unique demands on the family that reduced their odds of moving out of poverty. 
Beyond describing the family economic predictors and consequences of child NDs, these results also show the sensitivity of economic indicators used in social epidemiological research. Two patterns are worth noting. First, the risk for poverty is qualitatively different from the risk of economic hardship as evidenced by the different trajectories (see Figure 2). Proportionately more families were likely to experience persistent hardship than persistent poverty and the short transient hardship group experienced a sharp increase in risk over the early years that disappears by age 11 . The most comparable transient poverty group saw a gradual increase with sustained risk throughout the period. Second, unlike economic hardship, the risk for poverty associated with raising a child with a ND was largely explained by child, family, and caregiver covariates. In other words, having a child with a ND did not relate to experiencing more or less poverty during the years when the child is normally present in the home. Our results suggest that the risk of living in poverty is mostly explained by family socioeconomic characteristics that were present before the child was born. Previous cross-sectional studies that documented large differences in poverty between ND families and non-ND families (see e.g., Montes \& Halterman, 2008) may have overestimated the influence of ND on family economic wellbeing.

Disentangling the relation between ND status and family economic well-being is challenging primarily for selection reasons. Several studies have established that families that have a child with a ND are more likely to be poor than families raising children who do not have a ND (Emerson \& Hatton, 2009). The PSID’s rich intergenerational panel design allowed us to estimate the economic impacts of having a child with ND in ways that other studies have not. We examined the economic, social, and health circumstances at birth and five years prior to the birth of the child and analyzed prospective poverty and economic hardship trajectories. 
Some limitations of the study should be noted. First, the measure of ND includes some caveats. Disability status was based on parents' reports, and did not include all forms of ND such as Attention Deficit Hyperactivity Disorder (ADHD). As a result, observed differences may be conservatively biased because some families who were coded into the non-ND group may have actually had ND. Further, we were not able to observe the severity of the functional limitations associated with the ND condition or when the ND began. Research has demonstrated that the severity of a disability is strongly associated with experiencing labor market problems (Burton \& Phipps, 2009). Second, our study design did not control for period macroeconomic conditions such as economic growth or recession that might have affected poverty and economic hardship. However, we did control for childbirth year, which controlled some period effects. Third, we did not control for state level social assistance and other social welfare policies that were designed to offset and mitigate poverty risk. American social welfare assistance is increasingly devolved from federal responsibility to states and we would expect these to have some impact on poverty risk (Bruch, Meyers, \& Gornick, 2016). Further, although we investigated baseline socioeconomic variables, future analysis should examine changes in these variables over time. Lastly, the study may suffer an omitted variable bias where factors that affect both economic circumstances and ND status were unmeasured.

In summary, these findings provide new insights into child ND and its links to family economic well-being. Findings contribute descriptive evidence on the economic circumstances of families with a child with ND. In comparing families raising a child with ND to non-ND families, we document inequalities that pre-exist the child's birth and that remain throughout childhood and adolescence. Given the inequality in higher poverty risk, future research should seek to understand other economic factors and policy implications. For example, indicators of financial well-being such as financial assets and net worth/wealth 
(Parish, Rose, \& Swaine, 2010) could be studied in a prospective longitudinal design to better understand broader dimensions of well-being. Further, it is crucial to understand the role of social policies designed to offset inadequate market earnings. To what extent do income maintenance, tax credits, and social transfers offset the unique poverty risk of families raising a child with a ND? These policy questions are of primary importance given the obligations under the United Nations (1975) Declaration on the Rights of Disabled Persons and the Americans with Disabilities Act. 


\section{References}

American Academy of Pediatrics. (2016). Effect of child and family poverty on child health in the United States. Pediatrics, 137(4). Retrieved from http://pediatrics.aappublications.org/content/112/Supplement_3/707.short

Anderson, D., Dumont, S., Jacobs, P., \& Azzaria, L. (2007). The personal costs of caring for a child with a disability: a review of the literature. Public Health Reports, 122(1), 316.

Andruff, H., Carraro, N., Thompson, A., Gaudreau, P., \& Louvet, B. (2009). Latent class growth modelling: a tutorial. Tutorials in Quantitative Methods for Psychology, 5(1), $11-24$.

Arim, R. G., Garner, R. E., Brehaut, J. C., Lach, L. M., MacKenzie, M. J., Rosenbaum, P. L., \& Kohen, D. E. (2012). Contextual influences of parenting behaviors for children with neurodevelopmental disorders: results from a Canadian national survey. Disability and Rehabilitation, 34(26), 2222-2233.

Bane, M. J., \& Ellwood, D. T. (1986). Slipping into and out of poverty: The dynamics of spells. Journal of Human Resources, 21(1), 1-23.

Blackburn, C. M., Spencer, N. J., \& Read, J. M. (2013). Is the onset of disabling chronic conditions in later childhood associated with exposure to social disadvantage in earlier childhood? A prospective cohort study using the ONS Longitudinal Study for England and Wales. BMC Pediatrics, 13, 101. https://doi.org/10.1186/1471-2431-13101

Blank, R. M. (2008). Presidential address: How to improve poverty measurement in the United States. Journal of Policy Analysis and Management, 27(2), 233-254. https://doi.org/10.1002/pam.20323 
Brault, M. (2010). Americans with Disabilities: 2010. Washington D. C.: U.S. Census Bureau. Retrieved from http://www.census.gov/people/disability/publications/sipp2010.html

Bruch, S., Meyers, M., \& Gornick, J. (2016). Separate and unequal: The dimensions and consequences of safety net decentralization in the U.S. 1994-2014 (No. DP 1432-16). Madison, WI: Institute for Research on Poverty.

Burton, P., \& Phipps, S. (2009). Economic costs of caring for children with disabilities in Canada. Canadian Public Policy, 35(3), 269-290.

Cidav, Z., Marcus, S. C., \& Mandell, D. S. (2012). Implications of childhood autism for parental employment and earnings. Pediatrics, 129(4), 617-623. https://doi.org/10.1542/peds.2011-2700

Cohen, P. N., \& Petrescu-Prahova, M. (2006). Gendered living arrangements among children with disabilities. Journal of Marriage and Family, 68(3), 630-638.

DeNavas-Walt, C., \& Proctor, B. (2015). Income and Poverty in the United States: 2014. Washington D. C.: U.S. Census Bureau. Retrieved from www.census.gov/content/dam/Census/library/publications/2015/demo/p60-252.pdf

Duncan, G. J., \& Brooks-Gunn, J. (1999). Consequences of growing up poor. New York: Russell Sage Foundation.

Duncan, G. J., Ziol-Guest, K. M., \& Kalil, A. (2010). Early-childhood poverty and adult attainment, behavior, and health. Child Development, 81(1), 306-325.

Emerson, E., \& Hatton, C. (2009). Socioeconomic position, poverty, and family research. International Review of Research in Mental Retardation, 37, 97-129.

Emerson, E., Shahtahmasebi, S., Lancaster, G., \& Berridge, D. (2010). Poverty transitions among families supporting a child with intellectual disability. Journal of Intellectual and Developmental Disability, 35(4), 224-234. 
Fujiura, G. T., \& Yamaki, K. (2000). Trends in demography of childhood poverty and disability. Exceptional Children, 66(2), 187-199.

Garner, R. E., Arim, R. G., Kohen, D. E., Lach, L. M., MacKenzie, M. J., Brehaut, J. C., \& Rosenbaum, P. L. (2013). Parenting children with neurodevelopmental disorders and/or behaviour problems. Child Care Health and Development, 39(3), 412-421. https://doi.org/10.1111/j.1365-2214.2011.01347.x

Genereaux, D., van Karnebeek, C. D., \& Birch, P. H. (2015). Costs of caring for children with an intellectual developmental disorder. Disability and Health Journal, 8(4), 646651.

Halfon, N., Houtrow, A., Larson, K., \& Newacheck, P. W. (2012). The changing landscape of disability in childhood. The Future of Children, 22(1), 13-42. https://doi.org/10.1353/foc.2012.0004

Hertzman, C. (1999). The biological embedding of early experience and its effects on health in adulthood. Annals of the New York Academy of Sciences, 896(1), 85-95.

Institute for Social Research. (2015). The Panel Study of Income Dynamics. University of Michigan. Retrieved from http://psidonline.isr.umich.edu

Joesch, J. M., \& Smith, K. R. (1997). Children’s health and their mothers' risk of divorce or separation. Social Biology, 44(3-4), 159-169.

Jones, B. L., Nagin, D. S., \& Roeder, K. (2001). A SAS procedure based on mixture models for estimating developmental trajectories. Sociological Methods \& Research, 29(3), 374-393.

Kröger, H., Pakpahan, E., \& Hoffmann, R. (2015). What causes health inequality? A systematic review on the relative importance of social causation and health selection. The European Journal of Public Health, 25(6), 951-960. https://doi.org/10.1093/eurpub/ckv111 
Kvist, A. P., Nielsen, H. S., \& Simonsen, M. (2013). The importance of children's ADHD for parents’ relationship stability and labor supply. Social Science \& Medicine, 88, 3038.

Lach, L., Kohen, D., Garner, R., Brehaut, J., Miller, A., Klassen, A., \& Rosenbaum, P. (2009). The health and psychosocial functioning of caregivers of children with neurodevelopmental disorders. Disability and Rehabilitation, 31(8), 607-618.

Lavelle, T. A., Weinstein, M. C., Newhouse, J. P., Munir, K., Kuhlthau, K. A., \& Prosser, L. A. (2014). Economic burden of childhood autism spectrum disorders. Pediatrics, 133(3), e520-e529.

Lewis, S., Kagan, C., \& Heaton, P. (2000). Dual-earner parents with disabled children family patterns for working and caring. Journal of Family Issues, 21(8), 1031-1060.

Lu, Z. H., \& Zuo, A. (2010). Effects of a child's disability on affected female’s labour supply in Australia. Australian Economic Papers, 49(3), 222-240. https://doi.org/10.1111/j.1467-8454.2010.00398.x

Lustig, D. C., \& Strauser, D. R. (2007). Causal relationships between poverty and disability. Rehabilitation Counseling Bulletin, 50(4), 194-202. https://doi.org/10.1177/00343552070500040101

Mauldon, J. (1992). Children’s risks of experiencing divorce and remarriage: do disabled children destabilize marriages? Population Studies, 46(2), 349-362.

McDonough, P., Sacker, A., \& Wiggins, R. D. (2005). Time on my side? Life course trajectories of poverty and health. Social Science \& Medicine, 61(8), 1795-1808. https://doi.org/10.1016/j.socscimed.2005.03.021

Montes, G., \& Halterman, J. S. (2008). Association of childhood autism spectrum disorders and loss of family income. Pediatrics, 121(4), e821-e826. 
Morris, C., Janssens, A., Tomlinson, R., Williams, J., \& Logan, S. (2013). Towards a definition of neurodisability: a Delphi survey. Developmental Medicine \& Child Neurology, 55(12), 1103-1108.

Nagin, D. S. (1999). Analyzing developmental trajectories: a semiparametric, group-based approach. Psychological Methods, 4(2), 139.

Palloni, A., Milesi, C., White, R. G., \& Turner, A. (2009). Early childhood health, reproduction of economic inequalities and the persistence of health and mortality differentials. Social Science \& Medicine, 68(9), 1574-1582.

Parish, S. L., Rose, R. A., \& Swaine, J. G. (2010). Financial well-being of US parents caring for coresident children and adults with developmental disabilities: An age cohort analysis. Journal of Intellectual \& Developmental Disability, 35(4), 235-243. https://doi.org/10.3109/13668250.2010.519331

Pascoe, J. M., Wood, D. L., Duffee, J. H., Kuo, A., Health, C. on P. A. of C. and F., \& Pediatrics, C. on C. (2016). Mediators and adverse effects of child poverty in the United States. Pediatrics, peds.2016-0340. https://doi.org/10.1542/peds.2016-0340

Porterfield, S. L. (2002). Work choices of mothers in families with children with disabilities. Journal of Marriage and Family, 64(4), 972-981. https://doi.org/10.1111/j.17413737.2002.00972.x

Power, C., Stansfeld, S. A., Matthews, S., Manor, O., \& Hope, S. (2002). Childhood and adulthood risk factors for socio-economic differentials in psychological distress: evidence from the 1958 British birth cohort. Social Science \& Medicine, 55(11), 1989-2004.

Rainwater, L., \& Smeeding, T. M. (2005). Poor kids in a rich country: America's children in comparative perspective. Russell Sage Foundation. 
Rank, M. R., \& Hirschl, T. A. (2001). Poverty across the life cycle: evidence from the PSID. Journal of Policy Analysis and Management, 20(4), 737-755. https://doi.org/10.1002/pam.1026

Saunders, B. S., Tilford, J. M., Fussell, J. J., Schulz, E. G., Casey, P. H., \& Kuo, D. Z. (2015). Financial and employment impact of intellectual disability on families of children with autism. Families, Systems, \& Health, 33(1), 36-45. https://doi.org/10.1037/fsh0000102

Shaefer, H. L., Edin, K., \& Talbert, E. (2015). Understanding the dynamics of \$2-a-day poverty in the United States. RSF. Retrieved from http://www.rsfjournal.org/doi/abs/10.7758/RSF.2015.1.1.07

Shahtahmasebi, S., Emerson, E., Berridge, D., \& Lancaster, G. (2011). Child disability and the dynamics of family poverty, hardship and financial strain: evidence from the UK. Journal of Social Policy, 40(4), 653-673.

Smeeding, T. (2016). Poverty measurement. In D. Brady \& L. Burton (Eds.), The Oxford handbook of poverty and society (pp. 21-46). Oxford, UK: Oxford University Press.

Stabile, M., \& Allin, S. (2012). The economic costs of childhood disability. The Future of Children, 22(1), 65-96.

United States Census Bureau. (2015). Poverty thresholds. Retrieved from https://www.census.gov/hhes/www/poverty/data/threshld/

Wehby, G. L., \& Ohsfeldt, R. L. (2007). The impact of having a young child with disabilities on maternal labor supply by race and marital status. Journal of Health and Human Services Administration, 30(3), 327-51.

Wolf, S., Gennetian, L. A., Morris, P. A., \& Hill, H. D. (2014). Patterns of income instability among low-and middle-income households with children. Family Relations, 63(3), 397-410. 
Zablotsky, B., Black, L. I., Maenner, M. J., Schieve, L. A., \& Blumberg, S. J. (2015).

Estimated prevalence of autism and other developmental disabilities following questionnaire changes in the 2014 National Health Interview Survey. Retrieved from https://stacks.cdc.gov/view/cdc/38790 
Figures and tables

Table 1. Characteristics of study participants at baseline (birth year of the child) by ND status

\begin{tabular}{|c|c|c|c|c|}
\hline & \multicolumn{2}{|c|}{$\begin{array}{l}\text { Children with a ND } \\
(\mathrm{n}=656)\end{array}$} & \multicolumn{2}{|c|}{$\begin{array}{l}\text { Children without a ND } \\
\qquad(\mathrm{n}=2661)\end{array}$} \\
\hline & $\begin{array}{l}\text { Weighted } \\
\%(n)\end{array}$ & $\begin{array}{c}\text { Weighted mean } \\
\text { (SD) }\end{array}$ & $\begin{array}{l}\text { Weighted \% } \\
\text { (n) }\end{array}$ & $\begin{array}{l}\text { Weighted mean } \\
\text { (SD) }\end{array}$ \\
\hline \multicolumn{5}{|l|}{ Primary Caregiver } \\
\hline Age (years) & & $27.78(7.25)$ & & $28.15(6.17)$ \\
\hline \multicolumn{5}{|l|}{ Gender } \\
\hline Female & $97.5(639)$ & & $97.0(2585)$ & \\
\hline \multicolumn{5}{|l|}{ Race/ethnicity } \\
\hline White & $71.6(338)$ & & $69.3(1268)$ & \\
\hline Black & $15.8(253)$ & & $16.1(1135)$ & \\
\hline Other & $12.6(58)$ & & $14.6(249)$ & \\
\hline \multicolumn{5}{|l|}{ Marital status } \\
\hline Married/partnered & $78.5(387)$ & & $82.5(1655)$ & \\
\hline Not married/partnered & $21.5(157)$ & & $17.5(614)$ & \\
\hline Years of education & & $13.37(2.46)$ & & $13.88(2.53)$ \\
\hline \multicolumn{5}{|l|}{ Working status } \\
\hline Working & $42.3(220)$ & & 50.7 (1036) & \\
\hline Not working & $57.7(298)$ & & 49.3 (1069) & \\
\hline \multicolumn{5}{|l|}{ Self-rated health } \\
\hline Good/very good/excellent & $88.8(474)$ & & $93.9(2025)$ & \\
\hline Fair/poor & $11.2(68)$ & & $6.1(236)$ & \\
\hline \multicolumn{5}{|l|}{ Household } \\
\hline Number of children & & $1.82(1.20)$ & & $1.62(1.07)$ \\
\hline Income (median, in 2013 USD) & & 49,836 $(47,646)$ & & 61,207 $(57,509)$ \\
\hline Income-to-needs ratio & & $3.06(2.51)$ & & $3.66(2.91)$ \\
\hline Poverty rate & $18.3(137)$ & & 11.5 (409) & \\
\hline Economic hardship rate & $30.4(208)$ & & $19.7(642)$ & \\
\hline
\end{tabular}

Note. $(n=3,317)$ Weighted using household survey weights. 
Figure 1. Predicted probability of family living below the poverty threshold (\%) and economic hardship, by age of child and ND status of child extended to 5 years before child birth.

a)

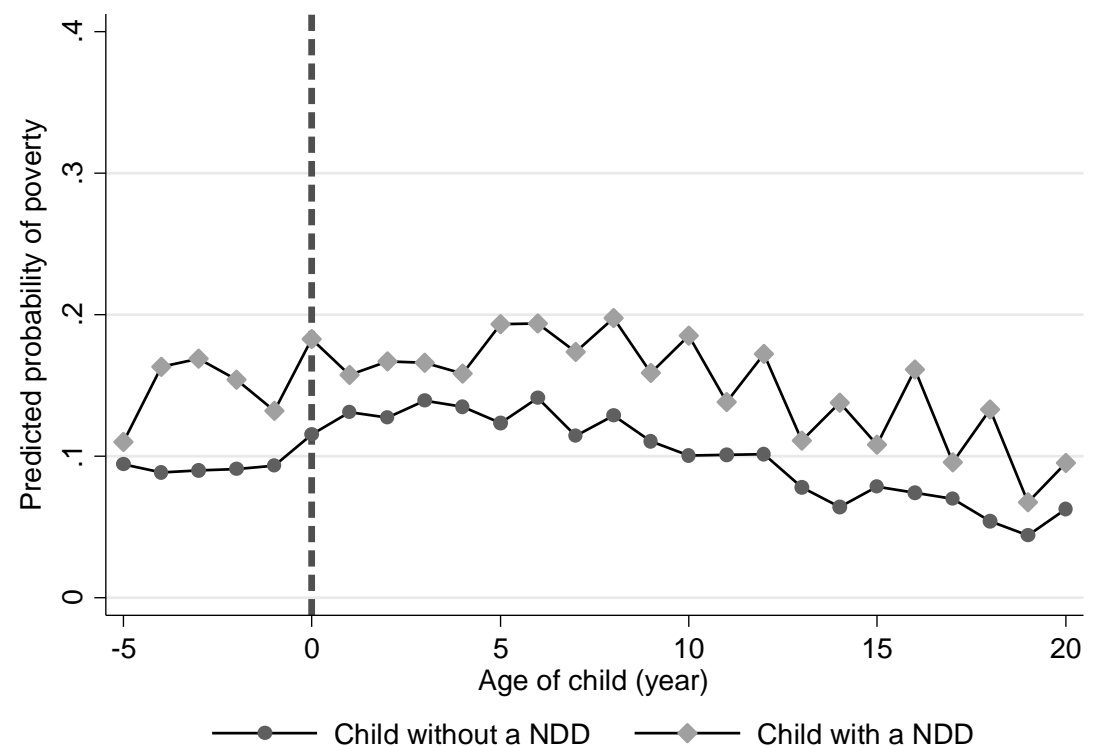

b)

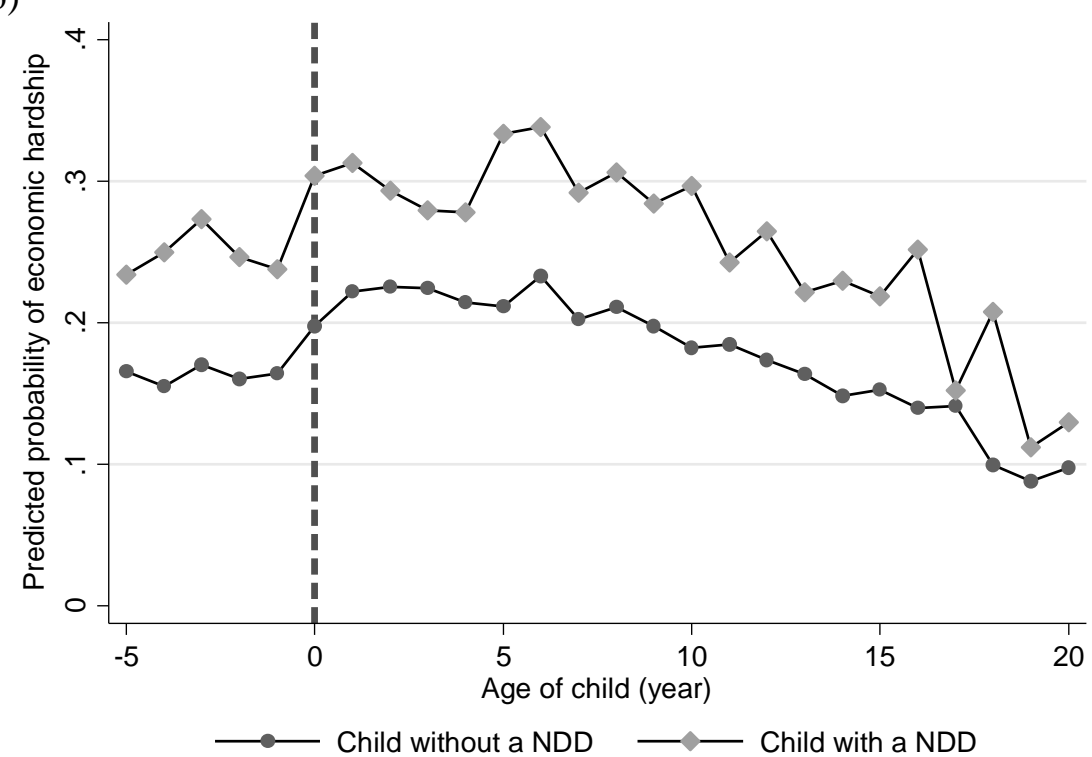

Legend. a) Predicted probability of family living below the poverty threshold; b) Predicted probability of family living at or below $150 \%$ income to need ratio. Models were weighted using household survey weights Bold dash indicates year of birth (age 0). 
Figure 2. Trajectory of probability of family poverty and income-to-need ratio among families with children, from 5 year before to 20 years after child birth

a) Trajectories of probability of family living below the national poverty threshold

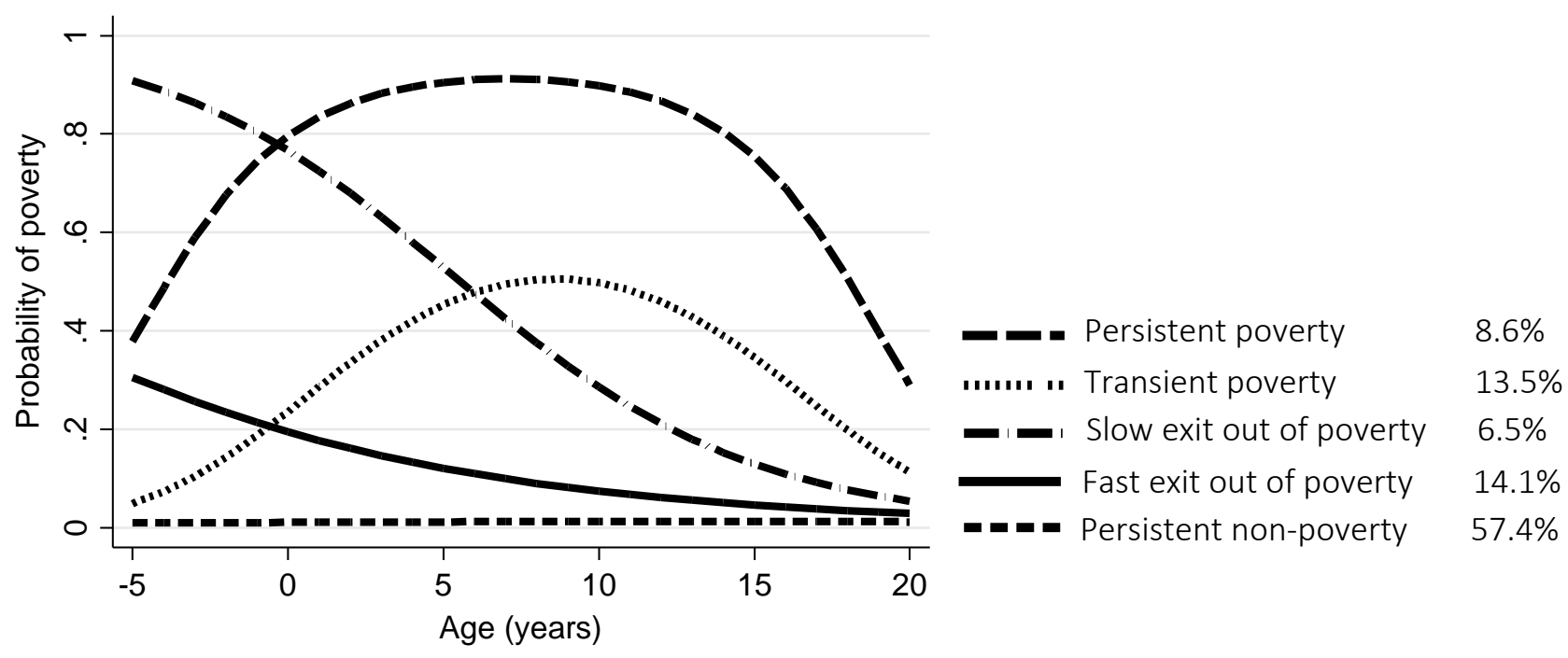

b) Trajectories of probability of family living in economic hardship (below $150 \%$ of the income-toneed ratio)

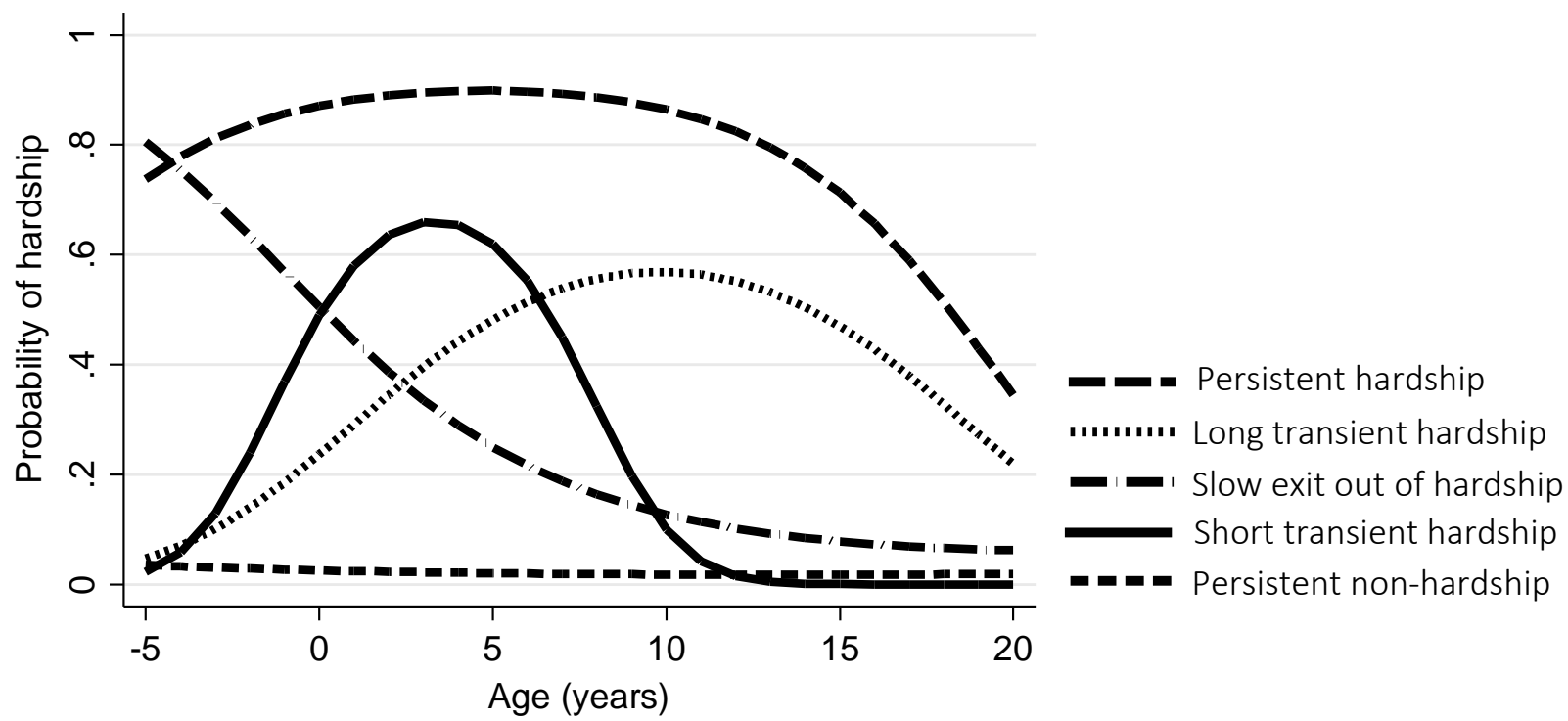

Legend. a) Trajectories of probability of family living below the national poverty threshold; b)

Trajectories of probability of family living below $150 \%$ of the income-to-need ratio 
Table 2. Characteristics of the child and the primary caregiver (PCG) the year prior to childbirth by trajectory of family poverty using national poverty threshold.

\begin{tabular}{|c|c|c|c|c|c|}
\hline & $\begin{array}{l}\text { Trajectory } 1 \\
\text { Persistent non- } \\
\text { poverty }\end{array}$ & $\begin{array}{l}\text { Trajectory } 2 \\
\text { Fast exit out of } \\
\text { poverty }\end{array}$ & $\begin{array}{l}\text { Trajectory } 3 \\
\text { Transient poverty }\end{array}$ & $\begin{array}{l}\text { Trajectory } 4 \\
\text { Slow exit out of } \\
\text { poverty }\end{array}$ & $\begin{array}{l}\text { Trajectory } 5 \\
\text { Persistent poverty }\end{array}$ \\
\hline \multirow[t]{2}{*}{$\%$ of the sample } & $57.4 \%$ & $14.1 \%$ & $13.5 \%$ & $6.5 \%$ & $8.6 \%$ \\
\hline & $\%(\mathrm{n})$ & $\%(n)$ & $\%(\mathrm{n})$ & $\%(n)$ & $\%(n)$ \\
\hline Child has a ND & $17.5(405)$ & $24.2(81)$ & $26.2(101)$ & $32.6(39)$ & $28.8(45)$ \\
\hline \multicolumn{6}{|l|}{ Child gender } \\
\hline Male & 48.9 (1079) & $56(181)$ & $49.2(173)$ & $55.4(65)$ & $47.4(69)$ \\
\hline Female & $51.1(1126)$ & $44(143)$ & $50.8(179)$ & $44.6(52)$ & $52.6(77)$ \\
\hline Age of PCG, mean (SD) & $28.9(6)$ & $26.3(6.2)$ & $25.7(6.7)$ & $25.9(6.6)$ & $26.8(8.7)$ \\
\hline \multicolumn{6}{|l|}{ Race of PCG } \\
\hline White & $78.8(1827)$ & $62.9(210)$ & 47.7 (184) & $34.6(42)$ & $21.9(34)$ \\
\hline Not white & $21.2(492)$ & $37.1(124)$ & $52.3(202)$ & $65.4(78)$ & $78.1(123)$ \\
\hline $\begin{array}{l}\text { Years of education of } \\
\text { PCG, mean (SD) }\end{array}$ & $14.2(2.4)$ & $13.4(2.1)$ & $12.7(2.8)$ & $12.9(2.1)$ & $11.3(2.8)$ \\
\hline \multicolumn{6}{|l|}{ Marital status of PCG } \\
\hline Married/partnered & $89.7(1790)$ & $61.4(180)$ & 54.5 (153) & $24.5(27)$ & $30.2(36)$ \\
\hline Not married/partnered & $10.3(206)$ & $38.6(113)$ & $45.5(128)$ & $75.5(84)$ & $69.8(83)$ \\
\hline \multicolumn{6}{|l|}{ Working status of PCG } \\
\hline Not Working & $32.4(575)$ & $52.2(133)$ & $55.3(129)$ & $71.2(67)$ & $71.6(75)$ \\
\hline Working & $67.6(1201)$ & $47.8(122)$ & 44.7 (104) & $28.8(27)$ & $28.4(30)$ \\
\hline \multicolumn{6}{|l|}{ Self-rated health of PCG } \\
\hline Excellent & 39.5 (788) & $21.9(65)$ & $15.4(43)$ & $21.5(24)$ & $15(18)$ \\
\hline Very good & $38.9(776)$ & $41.3(123)$ & $35.7(100)$ & $31.5(35)$ & $22(27)$ \\
\hline Good & $18.1(360)$ & $27.4(82)$ & $32(89)$ & $29.2(33)$ & $32.6(40)$ \\
\hline Fair & $2.7(53)$ & $6(18)$ & $14.1(39)$ & $15.5(17)$ & $25.8(31)$ \\
\hline Poor & $0.8(15)$ & $3.4(10)$ & $2.7(8)$ & $2.3(3)$ & $4.6(6)$ \\
\hline $\begin{array}{l}\text { Number of children in } \\
\text { household, mean (SD) }\end{array}$ & $1.5(1)$ & $1.8(1.1)$ & $1.7(1.2)$ & $2.6(1.5)$ & $2.4(1.3)$ \\
\hline
\end{tabular}


Table 3. Association between child ND status and family characteristics and trajectory of family poverty using national poverty threshold

\begin{tabular}{|c|c|c|c|}
\hline & $\begin{array}{l}\text { Model } 1 \\
\text { ND only }\end{array}$ & $\begin{array}{c}\text { Model } 2 \\
\text { Adjusted for child and } \\
\text { family covariates }\end{array}$ & $\begin{array}{c}\text { Model } 3 \\
\text { Adjusted for child, family } \\
\text { and caregiver covariates }\end{array}$ \\
\hline & $\begin{array}{l}\text { Child has ND } \\
\text { RRR (95\% CI) }\end{array}$ & $\begin{array}{c}\text { Child has ND } \\
\text { RRR }(95 \% \text { CI) }\end{array}$ & $\begin{array}{c}\text { Child has ND } \\
\text { RRR (95\% CI) }\end{array}$ \\
\hline Trajectory 1 & & & \\
\hline $\begin{array}{l}\text { Persistent non-poverty } \\
\text { Trajectory } 2\end{array}$ & Reference & Reference & Reference \\
\hline $\begin{array}{l}\text { Fast exit out of poverty } \\
\text { Trajectory } 3\end{array}$ & $1.50(1.06,2.14)$ & $1.48(0.99,2.2)$ & $1.26(0.80,2.00)$ \\
\hline Transient poverty & $1.68(1.19,2.38)$ & $1.70(1.08,2.70)$ & $1.41(0.84,2.36)$ \\
\hline $\begin{array}{l}\text { Trajectory } 4 \\
\text { Slow exit out of poverty }\end{array}$ & $2.28(1.33,3.93)$ & $1.91(1.05,3.48)$ & $1.88(0.90,3.93)$ \\
\hline Trajectory 5 & & & \\
\hline Persistent poverty & $1.91(1.21,3.02)$ & $1.87(1.05,3.33)$ & $1.47(0.63,3.45)$ \\
\hline Covariates included in the model & & & \\
\hline Child gender & & $\mathrm{x}$ & $\mathrm{x}$ \\
\hline Birth year of child & & $\mathrm{x}$ & $\mathrm{x}$ \\
\hline Number of children in household & & $\mathrm{x}$ & $\mathrm{x}$ \\
\hline Age of PCG & & & $\mathrm{x}$ \\
\hline Race of PCG & & & $\mathrm{x}$ \\
\hline Years of education of PCG & & & $\mathrm{x}$ \\
\hline Marital status of PCG & & & $\mathrm{x}$ \\
\hline Working status of PCG & & & $\mathrm{x}$ \\
\hline Self-rated health of PCG & & & $\mathrm{x}$ \\
\hline
\end{tabular}

Note. PCG: primary care giver. RRR: relative risk ratio. Estimates from multinomial logistic regression. All models weighted using household survey weights. Model 1 is unadjusted. Model 2 is adjusted for gender and birth year of the child and number of children in the household. Model 3 is adjusted for gender and birth year of the child; number of children in the household; age, race, years of education, marital status, working status, and self-rated health of primary caregiver at year of child birth. 
Table 4. Characteristics of the child and the primary caregiver (PCG) the year prior to childbirth by trajectory of family economic hardship.

\begin{tabular}{|c|c|c|c|c|c|}
\hline & $\begin{array}{l}\text { Trajectory } 1 \\
\text { Persistent non- } \\
\text { hardship }\end{array}$ & $\begin{array}{c}\text { Trajectory } 2 \\
\text { Short transient } \\
\text { hardship }\end{array}$ & $\begin{array}{l}\text { Trajectory } 3 \\
\text { Long transient } \\
\text { hardship }\end{array}$ & $\begin{array}{l}\text { Trajectory } 4 \\
\text { Slow exit out of } \\
\text { hardship }\end{array}$ & $\begin{array}{c}\text { Trajectory } 5 \\
\text { Persistent hardship }\end{array}$ \\
\hline \multirow[t]{2}{*}{$\%$ of the sample } & $49.0 \%$ & $7.5 \%$ & $14.3 \%$ & $10.4 \%$ & $18.7 \%$ \\
\hline & $\%(n)$ & $\%(n)$ & $\%(n)$ & $\%(n)$ & $\%(n)$ \\
\hline Child has a ND & $16.7(331)$ & $23.4(55)$ & $25.1(104)$ & $27(67)$ & $26.4(115)$ \\
\hline \multicolumn{6}{|l|}{ Child gender } \\
\hline Male & $49.9(944)$ & $49.7(111)$ & $51.3(199)$ & $50.8(118)$ & $48.1(195)$ \\
\hline Female & $50.1(949)$ & $50.3(112)$ & 48.7 (189) & $49.2(115)$ & $51.9(211)$ \\
\hline Age of PCG, mean (SD) & $29.4(6)$ & $26.5(5.4)$ & $26.8(6.6)$ & $25.1(5.7)$ & $25.9(7.3)$ \\
\hline \multicolumn{6}{|l|}{ Race of PCG } \\
\hline White & $82.3(1632)$ & $69.6(163)$ & $55.9(232)$ & $62.8(156)$ & 26.5 (116) \\
\hline Not white & $17.7(352)$ & $30.4(71)$ & $44.1(183)$ & $37.2(92)$ & $73.5(321)$ \\
\hline $\begin{array}{l}\text { Years of education of } \\
\text { PCG, mean (SD) }\end{array}$ & $14.6(2.1)$ & $13.3(2.4)$ & $12.7(2.3)$ & $13.3(1.7)$ & $11.6(3.1)$ \\
\hline \multicolumn{6}{|l|}{ Marital status of PCG } \\
\hline Married/partnered & $90.9(1599)$ & $66.5(128)$ & $71.7(228)$ & $54.3(132)$ & $34.4(99)$ \\
\hline Not married/partnered & $9.1(159)$ & $33.5(65)$ & $28.3(90)$ & $45.7(112)$ & $65.6(189)$ \\
\hline \multicolumn{6}{|l|}{ Working status of PCG } \\
\hline Not Working & $30.5(480)$ & $53.9(91)$ & $43.8(113)$ & 56 (118) & 70.5 (177) \\
\hline Working & $69.5(1094)$ & $46.1(78)$ & $56.2(145)$ & $44(93)$ & $29.5(74)$ \\
\hline \multicolumn{6}{|l|}{ Self-rated health of PCG } \\
\hline Excellent & $41.6(732)$ & $23.4(45)$ & $17.4(55)$ & $26.3(64)$ & $14.6(42)$ \\
\hline Very good & $38(668)$ & $45.8(88)$ & $42.4(134)$ & $38.8(94)$ & $26(76)$ \\
\hline Good & $17.4(306)$ & $26.9(51)$ & $30.5(97)$ & $23(56)$ & $32.3(94)$ \\
\hline Fair & $2.5(44)$ & $3(6)$ & $8.4(27)$ & 7.7 (19) & $22.1(64)$ \\
\hline Poor & $0.6(11)$ & $0.9(2)$ & $1.3(4)$ & $4.1(10)$ & $5(14)$ \\
\hline $\begin{array}{l}\text { Number of children in } \\
\text { household, mean (SD) }\end{array}$ & $1.5(1)$ & $1.8(1)$ & $1.5(1.1)$ & $2(1.2)$ & $2.4(1.4)$ \\
\hline
\end{tabular}


Table 5. Association between child ND status and family characteristics and trajectory of family economic hardship

\begin{tabular}{|c|c|c|c|}
\hline & $\begin{array}{l}\text { Model } 1 \\
\text { ND only }\end{array}$ & $\begin{array}{c}\text { Model } 2 \\
\text { Adjusted for child and } \\
\text { family covariates }\end{array}$ & $\begin{array}{c}\text { Model } 3 \\
\text { Adjusted for child, family } \\
\text { and caregiver covariates }\end{array}$ \\
\hline & $\begin{array}{l}\text { Child has ND } \\
\text { RRR (95\% CI) }\end{array}$ & $\begin{array}{c}\text { Child has ND } \\
\text { RRR (95\% CI) } \\
\end{array}$ & $\begin{array}{c}\text { Child has ND } \\
\text { RRR }(95 \% \text { CI) }\end{array}$ \\
\hline \multicolumn{4}{|l|}{ Trajectory 1} \\
\hline \multicolumn{4}{|l|}{ Trajectory 2} \\
\hline $\begin{array}{l}\text { Short transient hardship } \\
\text { Trajectory } 3\end{array}$ & \multicolumn{2}{|c|}{ Trajectory 3} & $1.13(0.64,1.99)$ \\
\hline \multicolumn{4}{|l|}{ Trajectory 4} \\
\hline $\begin{array}{l}\text { Slow exit out of hardship } \\
\text { Trajectory } 5\end{array}$ & $1.85(1.24,2.77)$ & $1.74(1.12,2.69)$ & $1.54(0.92,2.59)$ \\
\hline Persistent hardship & $1.79(1.29,2.49)$ & $2.19(1.44,3.34)$ & $2.15(1.19,3.87)$ \\
\hline \multicolumn{4}{|l|}{ Covariates included in the model } \\
\hline Child gender & & $\mathrm{x}$ & $\mathrm{x}$ \\
\hline Birth year of child & & $\mathrm{x}$ & $\mathrm{x}$ \\
\hline Number of children in household & & $\mathrm{x}$ & $\mathrm{x}$ \\
\hline Age of PCG & & & $\mathrm{x}$ \\
\hline Race of PCG & & & $\mathrm{x}$ \\
\hline Years of education of PCG & & & $\mathrm{x}$ \\
\hline Marital status of PCG & & & $\mathrm{x}$ \\
\hline Working status of PCG & & & $\mathrm{x}$ \\
\hline Self-rated health of PCG & & & $\mathrm{x}$ \\
\hline
\end{tabular}

Note. PCG: primary care giver. RRR: relative risk ratio. Estimates from multinomial logistic regression. All models weighted using household survey weights. Model 1 is unadjusted. Model 2 is adjusted for gender and birth year of the child and number of children in the household. Model 3 is adjusted for gender and birth year of the child; number of children in the household; age, race, years of education, marital status, working status, and self-rated health of primary caregiver at year of child birth. 